
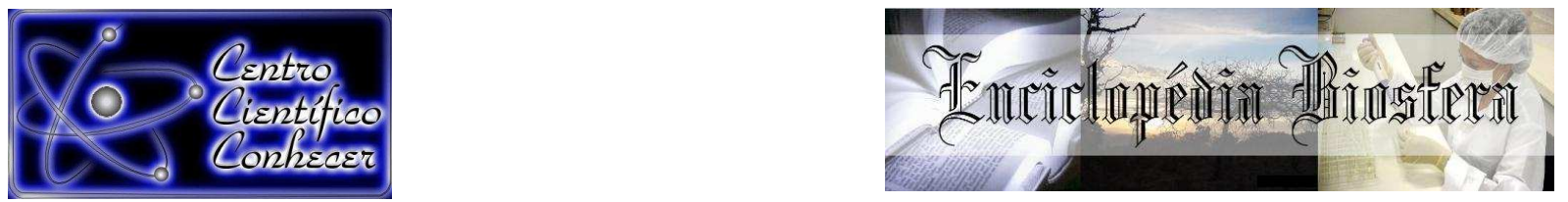

\title{
DIAGNÓSTICO SOBRE A FAUNA SILVESTRE APREENDIDA E DOADA EM BELÉM- PARÁ
}

\author{
Ana Lúcia Nunes Gutjahr ${ }^{1}$, Laíse Araújo dos Santos², Carlos Elias de Souza Braga ${ }^{3}$, \\ Raynon Joel Monteiro Alves ${ }^{4}$, \\ 1 Professora Doutora do Departamento de Ciências Naturais - UEPA \\ (melcam@uol.com.br), Belém-PA, Brasil \\ 2 Licenciada em Ciências Naturais, Belém-PA, Brasil \\ 3 Professor Doutor do Departamento de Ciências Naturais - UEPA, Paragominas-PA, \\ Brasil \\ 4 Mestre em Ciências Ambientais, Belém-PA, Brasil
}
Recebido em: 03/10/2016 - Aprovado em: 21/11/2016 - Publicado em: 05/12/2016
DOI: 10.18677/EnciBio 2016B 036

\begin{abstract}
RESUMO
O Brasil é reconhecido por sua grande biodiversidade e, por isso, é alvo de pessoas que utilizam a fauna silvestre indevidamente. Este estudo diagnosticou o banco digital da lista dos animais silvestres apreendidos ou doados ao IBAMA/Belém em 2010. Neste o ano foram apreendidos ou doados ao IBAMA 1.516 espécimes (900 aves, 451 répteis, 162 mamíferos e três aracnídeos), entre os quais seis espécies estão na lista de ameaçadas de extinção do Pará ( $n=59$ espécimes). Também, foi constatado que 1.108 espécimes não possuíam informação de seus locais de procedência. Além disso, - Batalhão Ambiental do Pará (BPA) foi a instituição que mais encaminhou animais para o IBAMA/Belém, devido as operações de apreensões. Conclui-se que a fauna silvestre amazônica, principalmente de aves, ainda é alvo frequente da venda ilícita, bem como de outras pessoas que as capturam para domesticá-las.
\end{abstract}

PALAVRAS-CHAVE: Domesticação. Região amazônica. Venda de animais.

\section{DIAGNOSIS ON THE WILD FAUNA, ORIGINATING FROM APPREHENSIONS AND DONATIONS, REGISTERED AT IBAMA, BELÉM-PARÁ}

\begin{abstract}
Brazil is recognized by his great biodiversity and, therefore, it is a target of persons who use the wild fauna unjustly. This study diagnosed the digital bank of registers of the wild animals confiscated or donated to IBAMA/Belém for the year of 2010. This year were confiscated or donated to IBAMA 1,516 specimens (900 birds, 451 reptiles, 162 mammals and three arachnids), including six species which are listed to be endangered of extinction in Pará ( $n=59$ specimens). Also, it was found that 1,108 specimens had no information of their origin sites. Besides, the Battalion of Environmental Policing of Para (BPA) was the institution that sent more animals to IBAMA/Belém, due to apprehension
\end{abstract}


operations It is concluded that the Amazon wildlife, especially birds, is still a frequent target of illegal trade, as well as others that capture to domesticate them.

KEYWORDS: Amazon region. Domestication. Traffic of wild animals.

\section{INTRODUÇÃO}

A fauna corresponde ao conjunto de todos os animais, aquáticos e terrestres, que coexistem em determinada área, região ou País, desempenhando funções em seu hábitat. Esta é considerada patrimônio da humanidade por sua incontestável importância ecológica, científica, econômica e cultural. Entretanto, grande parcela da sociedade não a reconhece como tal, causando-lhe inúmeros prejuízos, geralmente, irreversíveis, sobretudo ao se tratar da fauna que habita os ambientes naturais (VIDOLIN et al., 2004).

Deve-se considerar ainda que ações antrópicas as quais acometem a fauna estão classificadas em indiretas (desmatamento, poluição, queimadas e comércio extrativista) e diretas (caça, tráfico e captura para criação em cativeiro) (SILVA et al., 2008). Ressalta-se que a comercialização ilícita de animais selvagens contribui significativamente para a perda de biodiversidade, em termos de riqueza e de abundância, que aliados a outros fatores, pode causar a extinção de muitas espécies. Este segmento movimenta mundialmente de 10 a 20 bilhões de dólares, o que a torna a terceira maior atividade ilícita do mundo, posição no ranking inferior somente ao narcotráfico e a compra e venda ilegal das armas de fogo (GOMES \& OLIVEIRA, 2012; ZIMMERMAN, 2012), sendo que estes últimos estão em parte relacionados ao contrabando internacional de animais.

No Brasil, desde os primórdios, os índios já utilizavam animais silvestres, de forma sustentável, como alimento, alguns como xerimbabos [derivado do tupi, que significa "minha criação"] e partes deles como adereços para os rituais (ANTUNES, 2003; PESSOA et al., 2013). No entanto, desde os tempos coloniais, a exploração desordenada e predatória dessa biodiversidade vem deixando-a vulnerável, principalmente à extinção (RIBEIRO \& SILVA, 2007). A fauna silvestre brasileira é considerada propriedade do Estado e protegida pela Lei $N^{\circ} 9.605 / 1998$, a qual estabelece como proibitivo comprar, vender, criar e/ou realizar outro negócio em relação a essa fauna, tais práticas são consideradas crime ambiental inafiançável, salvo quando há a autorização do órgão competente (FElJó et al., 2010).

No território nacional, as regiões Norte, Nordeste e Centro-Oeste participam do contrabando da fauna nativa como áreas de captura e de pequenos e médios mercados, a região Sul como corredor e a Região Sudeste, como a grande consumidora e promotora do tráfico nacional e internacional (LOPES, 2003). As primeiras regiões supracitadas correspondem aos maiores biomas do Brasil em termos de extensão territorial e biodiversidade: Amazônia, Caatinga e o Cerrado (OJIMA \& MARTINE, 2012).

Na região Norte, o Estado do Pará representa $26 \%$ do território amazônico e a biodiversidade conhecida é catalogada em 2000 espécies de peixes, 950 de pássaros e 300 de mamíferos, além de ser uma das grandes áreas de transporte e contrabando dos animais selvagens, fazendo com que o tráfico seja o principal responsável para o desaparecimento da fauna nativa (SEMAS, 2006). 
Diante desse cenário, não somente a ação dos traficantes atinge intensamente a fauna silvestre, mas o quadro de degradação ambiental, resultado de anos de exploração descontrolada dos recursos ambientais, e as intenções das pessoas em domesticar os animais selvagens, desconsiderando todo o sofrimento e estresse dessas espécies, perante o convívio humano. Há situações ainda em que os "donos" percebem o trabalho e os cuidados especiais que os animais necessitarão, além da dificuldade financeira para mantê-los e, por tais razões, eles acabam abandonando-os ou doando-os para outro indivíduo (PEREIRA et al., 2010).

Neste aspecto, destaca-se também a entrega ou abandono do animal em uma instituição competente, como os zoológicos ou o IBAMA (PEREIRA et al., 2010). Para tanto, o IBAMA, como órgão de políticas e de fiscalização ambiental, tem ações e projetos, no âmbito estadual, como os CETAS, a fim de dar a estes adequada identificação, tratamento, triagem e destino, podendo haver parcerias com outras instituições públicas ou privadas para que possam manter estrutural e funcionalmente os CETAS (FREITAS et al., 2015).

Desta forma, verificar a atuação do tráfico ilegal da fauna, das apreensões e das doações de animais selvagens é extremamente importante no âmbito ambiental, visto que esse comércio ilícito contribui com a perda da biodiversidade. Assim, este estudo visou realizar um diagnóstico da fauna silvestre registrada pelo IBAMA/Belém, em 2010, com o propósito de gerar informações sobre o uso indevido de animais selvagens no Pará.

\section{MATERIAL E MÉTODOS}

O material analisado neste estudo se refere às informações de animais silvestres registrados no banco de dados digitalizado em planilhas do programa Microsoft Excel, pertencente à Divisão de Fauna da Superintendência (DFS) do Instituto Brasileiro do Meio Ambiente e dos Recursos Naturais Renováveis - IBAMA/Belém em 2010. Os registros das planilhas nos foram disponibilizados pelo responsável técnico da DFS/IBAMA/Belém. Ressalta-se que o banco de dados não está disponível livremente, por isso foi necessária a realização de um pedido formal e justificado, via memorando, ao IBAMA/Belém.

Para esta pesquisa, foram considerados os dados sobre o grupo taxonômico dos animais, as formas de entrada e de saída e a destinação final dos espécimes. Para isso, foram realizadas visitas periódicas autorizadas pela chefia desse órgão público e também previamente agendadas. Esses animais foram registrados na Instituição em uma planilha contendo: 1- Nome comum; 2- Nome científico; 3- Classe; 4- Ordem; 5Sexo; 6- Marcação; 7- Procedência; 8- Local de Origem; 9- Forma de entrada; 10- Data de Entrada; 11- Documento de Entrada; 12- Forma de Saída; 13- Data de saída; 14Documento de saída; 15- Local de saída; 16- Categoria; 17- Observações.

Os referidos registros do IBAMA/Belém permitiram inferir sobre as espécies de animais ameaçadas de extinção no Pará, segundo a lista divulgada pela Secretaria do Meio Ambiente e Sustentabilidade (SEMAS). As informações obtidas compuseram uma matriz informativa que foi elaborada no programa Microsoft Excel 2010 e, por meio desta, realizaram-se análises quantitativas, através de gráficos e tabelas, quanto aos animais apreendidos ou doados ao IBAMA/Belém, em 2010. 


\section{RESULTADOS E DISCUSSÃO Grupos taxonômicos dos animais registrados}

Durante o ano de 2010 a DFS do IBAMA/Belém registrou 1.516 animais resultado de apreensões e doações, sendo 1.513 vertebrados, pertencentes às classes Aves $(n=900)$, Répteis $(n=451)$ e Mamíferos $(n=162)$ e três invertebrados (Arachnida). Ressalta-se que foram catalogados três espécimes exóticos (dois periquitos australianos e uma tartaruga da China), o que corrobora o fato de que o mercado ilegal de animais não nativos ocorre internacionalmente. Além disso, deve-se considerar que introduzir espécies de animais invasores e/ou exóticos pode comprometer a biodiversidade local (SAMPAIO \& SCHMIDT, 2013) como por meio da competição interespecífica.

Entre os registros, a avifauna foi a mais frequente, contabilizando 16 ordens, 100 espécies e 900 espécimes. Quanto às ordens desse grupo, as mais representadas foram Passeriformes (37 espécies), com 579 exemplares, e Psittaciformes (20 espécies), com 120 espécimes, além de Craciiformes que foi a menos representativa com apenas uma espécie e um exemplar, a Mitu tuberosume (Spix, 1825) (Mutumcavalo) (Tabela 1). Destas, a Sporophila maximiliani (Cabanis, 1851) (53 indivíduos registrados) e a Guaruba guarouba (Gmelin, 1788) (três indivíduos), Anodorhynchus hyacinthinus (Latham, 1790) (um indivíduo) e Crax fasciolata pinima (Spix, 1825) (um indivíduo), popularmente conhecidas como bicudo, ararajuba, arara-azul-grande e mutum-de-penacho, respectivamente, estão entre as aves ameaçadas de extinção no Estado do Pará (SEMAS, 2006).

Registros de apreensões em diferentes regiões brasileiras, tais como na Paraíba (PESSOA et al., 2013) e no Piauí (MOURA et al., 2012), corroboram com o observado neste estudo, indicando que as aves são os animais mais comercializados de forma ilegal no País. Isso ocorre em razão da beleza da plumagem de muitas espécies, pela sua vocalização e, além disso, as aves são consideradas espécies de companhia pela população (FRANCO et al., 2012; SOUZA \& VILELA, 2013), condenando-as ao aprisionamento em gaiolas.

Sob essas condições encontram-se os Passeriformes (pássaros), visto que cada espécie canta diferente e harmoniosamente, tornando-os preferidos dos comerciantes e das pessoas em geral (PAGANO et al., 2009). Os resultados evidenciam que os Psitaciformes, principalmente os papagaios, compõem o segundo grupo da avifauna mais domesticada e frequente nos registros do IBAMA/Belém, o que é motivado pela capacidade em reproduzir palavras e/ou frases similares as do ser humano, consistindo num atrativo para a criação em ambiente doméstico. Todavia, o tráfico ilegal das aves canoras é facilitado pelo pequeno porte das mesmas e a facilidade de mantê-las em cativeiro, pois podem ser acondicionadas, em grande quantidade, em espaços diminutos (FRANCO et al., 2012; SOUZA \& VILELA, 2013).

Geralmente, as aves, principalmente os passeriformes, são capturadas na natureza durante o período reprodutivo, quando os machos estão competindo por meio da vocalização para atrair a atenção das fêmeas, assim, esse ato humano inviabiliza a reprodução e a manutenção das espécies no seu habitat natural, como o da Sporophila angolensis (Linnaeus, 1766) conhecida vulgarmente como curió (SOUZA \& VILELA, 
2013), os quais foram registrados, pelo IBAMA/Belém, 360 exemplares, ou seja, $23,7 \%$ do total de registro no IBAMA/Belém em 2010.

Em virtude desta prática, os passeriformes de pequeno porte tem apresentado uma grande redução populacional e possuem sério risco de extinção no Brasil, principalmente o Curió e o Bicudo (Sporophila maximilianı), os quais são bastante procurados por colecionadores de pássaros. Ressalta-se ainda que o Curió se encontra na lista de espécies vulneráveis ou em perigo nos estados de São Paulo, Paraná, Rio Grande do Sul e Minas Gerais(RENCTAS, 2009).

TABELA 1 - Ordens, quantificação de espécies e abundância de exemplares de aves registrados no IBAMA/Belém em 2010.

\begin{tabular}{ccc}
\hline Ordens & $\begin{array}{c}\text { Quantificação de } \\
\text { espécies }\end{array}$ & $\begin{array}{c}\text { Abundância de } \\
\text { Exemplares }\end{array}$ \\
\hline Anseriformes & 1 & 3 \\
Caprimulgiformes & 2 & 4 \\
Cathartiformes & 2 & 5 \\
Ciconiformes & 3 & 49 \\
Columbiformes & 2 & 2 \\
Coraciiformes & 2 & 5 \\
Craciiformes & 1 & 1 \\
Falconiformes & 10 & 32 \\
Galliformes & 4 & 11 \\
Gruiformes & 4 & 13 \\
Passeriformes & 37 & 579 \\
Pelecaniformes & 2 & 5 \\
Piciformes & 5 & 16 \\
Psittaciformes & 20 & 120 \\
Strigiformes & 6 & 51 \\
Trochiliformes & 1 & 4 \\
\hline Total & 100 & 900 \\
\hline
\end{tabular}

Fonte: DFS (2010).

Quanto à classe Reptilia (répteis), esta foi representada por três ordens, 26 espécies e 451 espécimes. Deste grupo, a ordem Testudines foi a que possuiu a maior quantidade de espécies registradas foi a ( $n=13$ espécies), com 310 exemplares, enquanto que a menos expressiva foi a Crocodylia ( $n=2$ espécies), com 15 indivíduos (Tabela 2). 
TABELA 2 - Ordens, quantificação de espécies e abundância de exemplares de répteis registrados no IBAMA/Belém, em 2010.

\begin{tabular}{ccc}
\hline Ordens & $\begin{array}{c}\text { Quantificação de } \\
\text { espécies }\end{array}$ & $\begin{array}{c}\text { Abundância de } \\
\text { exemplares }\end{array}$ \\
\hline Crocodylia & 2 & 15 \\
Squamata & 11 & 126 \\
Testudines & 13 & 310 \\
\hline Total & $\mathbf{2 6}$ & $\mathbf{4 5 1}$ \\
\hline
\end{tabular}

Fonte: DFS (2010).

Quanto à ordem Testudines, a espécie Rhinoclemmys punctularia (Daudin, 1801), conhecida como aperema, foi a mais frequente $(\mathrm{n}=81$ indivíduos). Ressalta-se que outros Testudines como os jabutis, as tartarugas e afins possuem importância como xerimbabo (animal doméstico) e alimentícia, visto que suas carnes compõem pratos típicos, principalmente da culinária nortista, e são comumente criados em residências.

Além disso, os ovos desses animais amazônicos também são bastante apreciados para a alimentação, sobretudo, pelas populações ribeirinhas, o que compromete a reprodução dessas espécies. Ressalta-se que a caça predatória e a coleta de ovos dos Testudines irão gradativamente dificultar a captura de várias de suas espécies que são apreciadas como alimento, pelas comunidades tradicionais humanas e tem também contribuído para agravar a ameaça de desaparecimento dessas espécies na natureza (FUCCIO et al., 2003).

No território brasileiro, os quelônios, em particular, os jabutis, Geochelone denticulata (Linnaeus, 1766), são mais comercializados de forma ilegal em razão de serem belas, mansas, sua facilidade de adaptação, alta capacidade reprodutiva no cativeiro e por seu transporte facilitado (CONCEIÇÃO et al., 2011). Outros Squamata, da subordem Serpentes, como Eunectes murinus (Linnaeus, 1758) e Boa constrictor (Linnaeus, 1758) e, denominadas popularmente como sucuri e jiboia, respectivamente, são levados pelo IBAMA ao serem encontrados nas residências, isso quando não são sacrificadas por populares. Além disso, esse grupo de animais é vislumbrado por causa do couro, utilizado na indústria de calçados e bolsas, assim como os representantes da Ordem Crocodylia (jacarés).

As várias utilidades e os negócios mais rentáveis podem conferir aos répteis, na maioria dos casos, o segundo grupo de animais mais requisitado pelo comércio ilegal, conforme observado no presente estudo e em outros realizados em diferentes regiões do Brasil (NASCIMENTO et al., 2010; MOURA et al., 2012).

Tratando-se da Classe dos Mamallia (mamíferos), registrada no IBAMA/Belém, ressalta-se foram quantificadas sete ordens, 30 espécies e 162 exemplares. A ordem Carnívora foi apresentou a quantidade de registros ( $n=9$ espécies), com 57 indivíduos, e as de menor representatividade, destacaram-se Sirenia (peixe-boi) e Chiroptera (morcego), ambas com uma espécie e um espécime (Tabela 3). Verificou-se ainda que a Panthera onca (Linnaeus, 1758) $(n=1)$ e o Trichechus inunguis (Natterer, 1883) $(n=$ 
1), conhecidos respectivamente por onça-pintada e peixe-boi-amazônico, estão na lista das espécies vulneráveis e ameaçadas de extinção no Pará (SEMAS, 2006).

TABELA 3 - Ordens, quantificação de espécies e abundância de exemplares de mamíferos registradas no IBAMA/Belém, em 2010.

\begin{tabular}{ccc}
\hline Ordens & $\begin{array}{c}\text { Quantificação de } \\
\text { espécies }\end{array}$ & $\begin{array}{c}\text { Abundância de } \\
\text { exemplares }\end{array}$ \\
\hline Artiodactyla & 2 & 2 \\
Carnivora & 9 & 57 \\
Chiroptera & 1 & 1 \\
Primates & 6 & 44 \\
Rodentia & 4 & 6 \\
Sirenia & 1 & 1 \\
Edentata & 6 & 51 \\
\hline Total & $\mathbf{3 0}$ & $\mathbf{1 6 2}$ \\
\hline
\end{tabular}

Fonte: DFS (2010).

Entre os registros de Carnívora, o quati, Nasua nasua (Linnaeus, 1766) foi a de maior frequência com 41 exemplares listados, isso pode estar relacionado ao fato de que a pele do animal é usada na confecção de adornos e vestimentas, na alimentação e também como xerimbabo, pois possuem um comportamento bem semelhante ao de cachorros domésticos.

Em particular, os carnívoros são muito procurados por colecionadores e por parques zoológicos, pois são, em sua maioria, de grande porte e muito atrativos para a população, sendo cobiçados para ambientes de exposição pública. Dessa forma, tornam-se alvos constantes da venda ilegal.

As espécies da Ordem Edentata como os tamanduás e a preguiça-comum, Bradypus variegatus (Schinz, 1825) são procurados para culinária regional, principalmente no Norte do Brasil. Geralmente são caçados e posteriormente vendidos a terceiros, o que faz parte do "tráfico sob encomenda", onde a pessoa paga alguém para caçar os animais de interesse (RIBEIRO, 2007).

Os primatas são comumente vítimas da biopirataria em estudos científicos. As espécies, como a Saimiri sciureus (Linnaeus, 1758) e Saguinus niger (É. Geoffroy, 1803), conhecidos respectivamente como mico-de-cheiro e sagui-una, podem ser encontradas em residências, sendo tratadas como animais domésticos ou estimação pelas pessoas.

Diante disso, há de se considerar que os animais silvestres sofrem estresse desde a remoção de seu hábitat natural, no transporte e na adaptação ao cativeiro. Além disso, esses animais podem ser transmitir doenças (zoonoses) aos humanos, que muitas vezes, desconhecem essa informação (ZAGO, 2008; FRAGA et al., 2011).

Deve-se destacar ainda que as ações antrópicas têm contribuído drasticamente para a diminuição das populações de mamíferos (FERREIRA et al., 2008), principalmente na extinção local desses animais, ocasionando desequilíbrio e/ou danos

ENCICLOPÉDIA BIOSFERA, Centro Científico Conhecer - Goiânia, v.13 n.24; p.403 2016 
irreparáveis aos ecossistemas. Entre essas ações, destaca-se a caça e o desmatamento como fatores que mais contribuem na diminuição da densidade dos mamíferos terrestres, tornando-os mais vulneráveis às ameaças de extinção (LOPES \& FERRARI, 2000; RIBEIRO et al., 2007).

Vale ressaltar que os aracnídeos (uma espécie e três indivíduos) foram os únicos invertebrados registrados, nas apreensões, pelo IBAMA/Belém. Tal fato deve-se a pouca atratividade desses animais por parte das pessoas, pois é raro encontrá-los como animal de estimação, além do que na maioria das vezes os mesmos são exterminados, por serem considerados peçonhentos ou asquerosos pela população.

\section{Procedência dos animais registrados no IBAMA/Belém}

Quanto à procedência dos animais registrados, a maioria $(n=1.109)$ teve origem não informada, 226 foram originários de Belém e 136 do município de Marituba (Tabela 4). Sobre isso, omitir o local de origem dos animais aos órgãos ambientais pode estar relacionado ao receio das pessoas em comprometer sua integridade física, visto que é sabido que os comerciantes de fauna são criminosos e, por isso, capazes de violências contra os denunciantes que podem intervir nos negócios ilegais.

As formas de entrada dos animais nos registros do IBAMA/Belém são decorrentes de diferentes maneiras, dentre elas destacam-se as apreensões do IBAMA $(n=423)$ e as doações $(n=455)$ (Figura 1). A Polícia Ambiental do Pará (BPA) foi quem mais colaborou com a entrega da fauna ao IBAMA/Belém $(n=477)$, visto que 0 BPA conta com um efetivo de cerca de 200 soldados e um grande número de veículos de transporte, tornando-se assim mais acessível, no que diz respeito a apreensão e/ou doação por parte da população. Conforme observado em outros estudos, parte das apreensões são atribuídas às Instituições de fiscalização, como a Polícia Ambiental, o que evidencia a relevância das mesmas para a proteção da biodiversidade, particularmente, da fauna silvestre (SANTOS et al., 2011; FREITAS et al., 2015).

Quanto às doações, estas podem ser particulares, quando as entregas ocorrem em órgãos, como o Corpo de Bombeiros, a Secretaria de Meio Ambiente e de Sustentabilidade (SEMAS), a Delegacia Especializada em Meio Ambiente (DEMA) e as doações voluntárias ao IBAMA. Nesta última situação, geralmente, o doador mente ou omite as informações de procedência do animal, pois grande parte da população acredita que pagará multas ou será presa e, por isso, tal impressão errônea contribui ainda mais para a ocorrência de abandono do espécime na rua ou em frente às instituições supracitadas.

Nesta condição houve dois registros referentes a dois jabutis da espécie Geochelone denticulata (Linnaeus, 1766) que foram abandonados em um táxi. No cenário nacional, pode-se inferir que descobrir o verdadeiro local onde correu a captura dos animais retirados da natureza é uma ação das mais árduas para as Instituições competentes, visto que o lugar de apreensão dos animais geralmente difere de onde eles foram retirados da natureza (HERNANDEZ \& CARVALHO, 2006). 
TABELA 4 - Município de procedência dos animais registrados no IBAMA/Belém no ano de 2010.

\begin{tabular}{cc}
\hline Município de procedência dos animais & Número de exemplares apreendidos ou doados \\
\hline Ananindeua & 12 \\
Barcarena & 3 \\
Belém & 226 \\
Bragança & 1 \\
Bujaru & 1 \\
Cametá & 1 \\
Castanhal & 1 \\
Goianésia do Pará & 2 \\
Igarapé-açu & 1 \\
Igarapé-mirim & 1 \\
Irituia & 1 \\
Marapanim & 1 \\
Marituba & 136 \\
Moju & 4 \\
Nova Esperança do Piriá & 2 \\
Santa Izabel do Pará & 2 \\
Santa Maria do Pará & 5 \\
Santo Antônio do Tauá & 4 \\
Terra Alta & 2 \\
Vigia & 2 \\
Não informado & 1108 \\
\hline & 1516 \\
\hline
\end{tabular}

Fonte: DFS (2010).

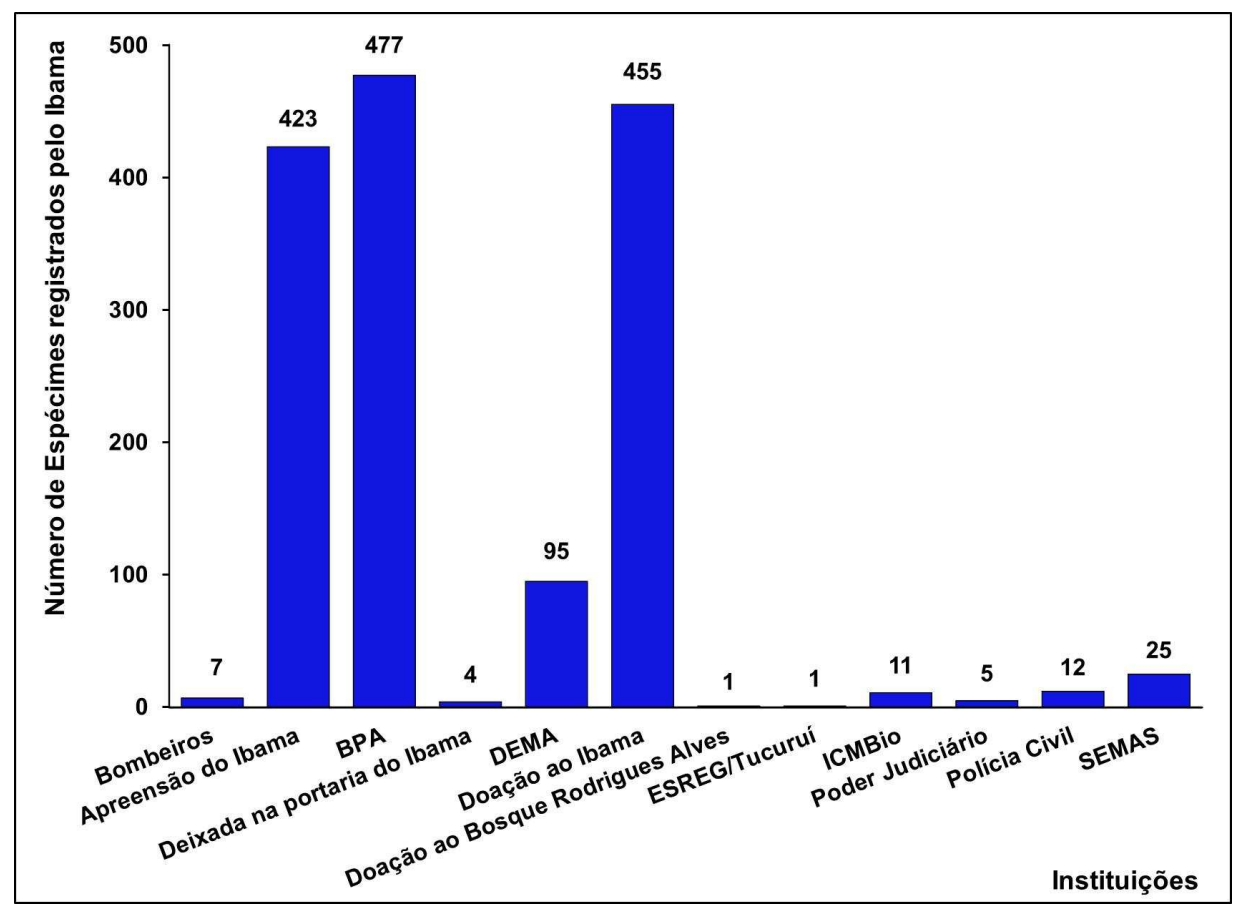

FIGURA 1 Quantidade de espécimes por instituições que encaminharam animais silvestres para o IBAMA/Belém, em 2010. Fonte: DFS (2010).

ENCICLOPÉDIA BIOSFERA, Centro Científico Conhecer - Goiânia, v.13 n.24; p.405 
Ressalta-se ainda que os registros de animais apreendidos poderiam ser maiores durante $o$ ano analisado, visto que o IBAMA apresenta um pequeno efetivo para atuar em todo o Estado do Pará. Além da quantidade reduzida de pessoas treinadas, ainda há casos de ausência ou insuficiência de equipamentos necessários para os resgates, apreensões e buscas dos animais silvestres (ANTUNES, 2005).

\section{Saída e destinação final dos animais}

A maioria $(n=753)$ dos 1.516 animais registrados no IBAMA/Belém teve como destino final, permanecer sob a guarda de outra instituição, a qual apresenta pessoal técnico capacitado e treinado, como por exemplo, parques zoológicos que possuem quarentena e criadouros conservacionistas. Do total, 704 foram soltos após sua completa recuperação e 45 foram a óbito em decorrência dos maus tratos, da baixa resistência ou pelo stress que o animal passou durante o transporte, além do sacrifício de 14 para amenizar o sofrimento (Figura 2).

O Parque Estadual do Utinga (PEUt) foi a principal instituição receptora de animais, o equivalente a 449 espécimes, seguida dos parques zoobotânicos Mangal das Garças $(n=260)$ e do Museu Paraense Emílio Goeldi $(n=203)$ e Jardim Botânico Bosque Rodrigues Alves ( $n=132$ ). Houve, ainda, uma grande quantidade de animais enviados aos criadouros conservacionistas $(n=171)$, a exemplo, do Criadouro Paricuiã $(n=121)$.

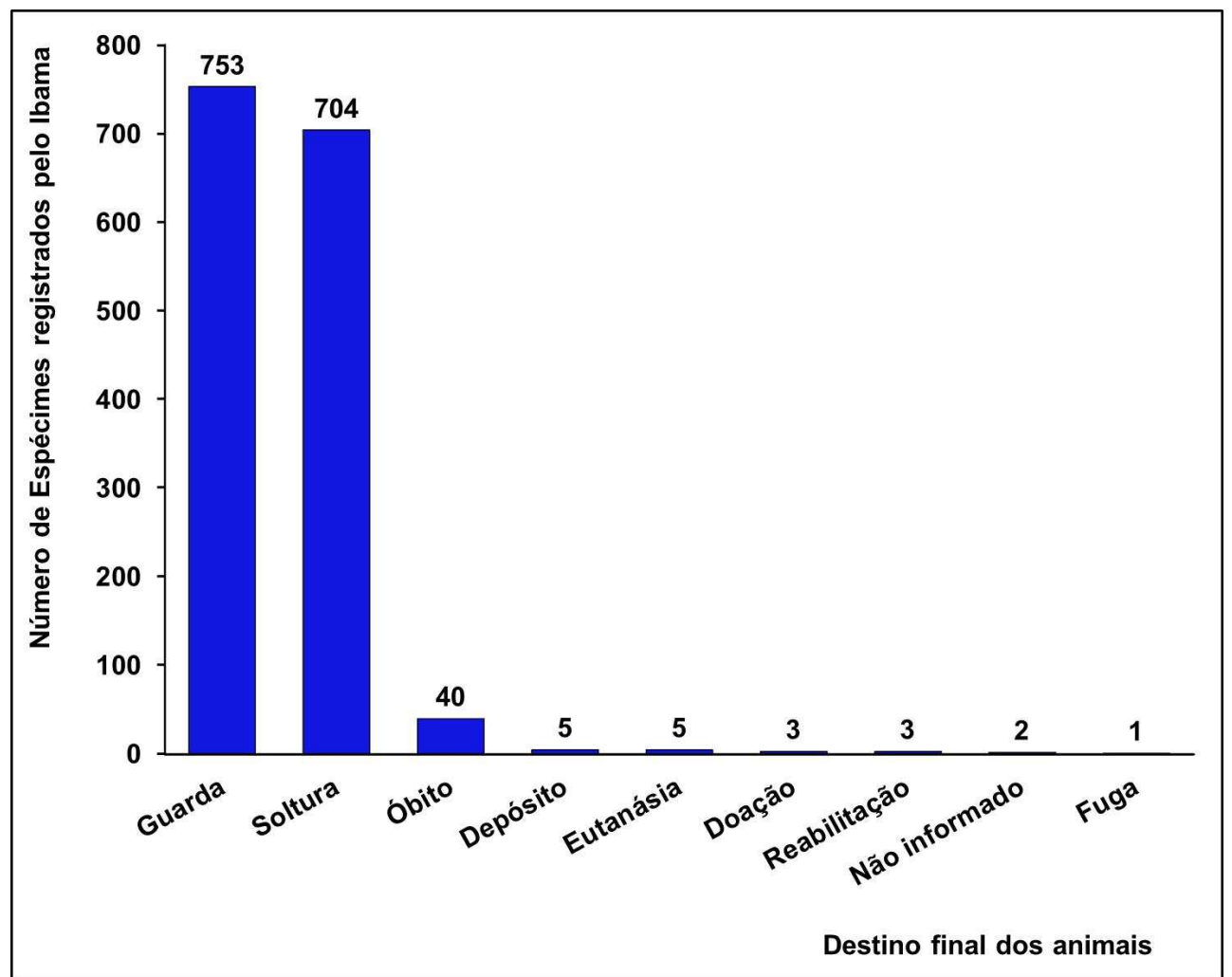

FIGURA 2 Quantidade de espécimes por locais de destinação final de animais registrados no IBAMA/Belém, em 2010. Fonte: (DFS, 2010). 
Cabe ressaltar que houveram dois fatos intrigantes, somente dois espécimes foram destinados ao CETAS/Belém, quando este deveria ser o maior receptor de animais apreendidos e doados, pois se trata de um órgão do próprio IBAMA, e 51 espécimes foram designados às áreas desconhecidas ou não registradas, o que dificulta as estatísticas de monitoramento do IBAMA.

É sabido que o Parque Estadual do Utinga contém as condições naturais preservadas, as quais oferecem proteção aos animais em ambiente livre, função que pertence ao BPA e a SEMAS. Quanto a isso, as Unidades de Conservação (UC) são consideradas estratégias importantes para a conservação e bem-estar das espécies silvestres (SILVA et al., 2008). Porém, a soltura de novos indivíduos nessas áreas representa um risco às condições originais do hábitat. Isso porque, não há a quantificação da capacidade de suporte do ambiente, e possíveis zoonoses podem ser introduzidas na fauna local (VIDOLIN et al., 2004). Portanto, segundo esses autores, a instituição fiscalizadora que decide pela soltura dos animais apreendidos precisa na totalidade dos casos, de suporte técnico para o processo de reabilitação dessas espécies.

Em geral, os parques zoológicos ou instituições similares são muito procurados para a destinação final dos animais silvestres apreendidos. No município de Belém, destacam-se o Parque Zoobotânico Mangal das Garças, Jardim Botânico Bosque Rodrigues Alves e o Parque Zoobotânico do Museu Paraense Emílio Goeldi, os quais são bastante requisitados para o acolhimento de animais apreendidos.

A preferência na destinação final de animais apreendidos por essas instituições é instituída pela legislação brasileira (Lei 9605/98 e Decreto-Lei 3179/99), a qual estabelece que esses animais devem ser encaminhados a zoológicos ou afins, em função destes possuírem equipe técnica capacitada e treinada para tal situação, e que após a devida adaptação os animais sejam soltos em seu habitat natural (KIERULFF et al., 2007). Essa prática é bastante comum em vários países, no entanto, devido ao grande número de apreensões, esta escolha tem se torna inviável, devido às instituições acolhedoras não possuírem espaço, recursos e pessoal suficientes para a manutenção desses animais (DIAS JÚNIOR et al., 2013).

Diante dos resultados obtidos neste estudo, verifica-se que se não forem estabelecidas políticas públicas eficazes protetivas para fauna brasileira, tais como de combate à degradação ambiental (desmatamento, exploração madeireira e expansão populacional humana), a qual gera perda de habitat (KLINK \& MACHADO, 2005, JORGE et al., 2013) e consequentemente de biodiversidade (PILLAR \& VÉLEZ, 2010) e, principalmente, de combate ao tráfico de animais silvestres no Brasil, sejam estes para abastecerem o mercado negro de colecionadores, zoológicos, pet shop ou de biopirataria (RENCTAS, 2014), cujo mercado ilegal movimenta 1,5 bilhões de dólares anualmente no Brasil (MACHADO et al., 2013) e 10 a 20 bilhões de dólares no mundo (GOMES \& OLIVEIRA, 2012; ZIMMERMAN, 2012) e ocasiona na retirada de 12 a 38 milhões de animais por ano da fauna brasileira (ROCHA et al., 2006), entre os quais 90\% morrem antes de chegarem ao destino final (DELABARY, 2012), teremos um cenário futuro de extinção em massa e desequilíbrio ambiental, irreparáveis e irreversíveis.

Entre as medidas de proteção da fauna brasileira, as quais poderiam contribuir 
para a redução da ameaça de extinção dos animais silvestres, pode-se destacar a de conscientização da população quanto à importância ambiental e utilização de animais silvestres (criação, comercialização e alimentação). Estabelecer leis as quais permitam que os animais silvestres se tornem fontes renováveis, através de implementação de criadouros autorizados, ambientes que permitam a caça esportiva e, ainda a de reprodução autorizada em cativeiro (PIRES et al., 2015). Além de se fortalecer as leis ambientais, que poderiam estabelecer um tipo específico de legislação penal com penas mais rígidas, visto que a atual é muito branda, onde as penas de reclusão podem variar de apenas seis meses a no máximo cinco anos e multa (CARVALHO, 2006; OKI \& PANDEFF, 2016).

\section{CONCLUSÃO}

Pode-se concluir que as aves são o grupo de animais preferidos ou mais procurados para a comercialização ilegal (tráfico) dos animais silvestres, além disso, estas também foram a de maior predileção pelas pessoas que veem as aves, como animais que podem ser tratados como domésticos ou de estimação. O curió Sporophila angolensis foi a espécie com o maior número de registro no DFS/IBAMA/Belém. A maioria dos animais registrados não possui o local de procedência de onde foram apreendidos ou doados, devido às pessoas temerem represálias ou multas por parte do IBAMA ou ameaça dos traficantes de animais. O BPA foi o órgão que mais encaminhou animais para os cuidados do IBAMA/Belém.

\section{AGRADECIMENTOS}

Os autores agradem ao IBAMA de Belém, pelo bom atendimento e fornecimento dos dados que foram fundamentas para a realização desse trabalho.

\section{REFERÊNCIAS}

ANTUNES, D. A. A importância do comércio legal frente ao comércio ilegal de animais $\quad$ silvestres. $2004 . \quad$ Disponível em: $<$ http://www.abz.org.br/files.php?file=documentos/importancia 932203679.pdf>. Acesso em: 12 ago. 2016.

CARVALHO, E. S. Tráfico interno de fauna silvestre - pássaros. Direito Animal, p. 123237,2006

CONCEIÇÃO, A. M.; BARROS, S. L. B.; ALBUQUERQUE, I. M. B. Presença de corpos estranhos no aparelho digestório de jabutis piranga (Chelonoidis carbonaria): relato de caso. Acta Veterinaria Brasilica, v. 5, n. 2, p.197-202, 2011. doi: http://dx.doi.org/10.21708/avb.2011.5.2.2070.

DELABARY, B. F. Aspectos que influenciam os maus tratos contra animais no meio urbano. Revista Eletrônica em Gestão, Educação e Tecnologia Ambiental, v. 5, n. 5, p. 835-840, 2012.

DIAS JÚNIOR, M. B. F.; CUNHA, H. F. A.; DIAS, T. C. A. C. Análise da destinação da 
fauna silvestre apreendida no Estado do Amapá, Brasil. Revista Internacional de Direito Ambiental e Políticas Públicas, n. 5, p. 23-36, 2013.

FEIJÓ, A. G.S.; SANTOS, C. I.; GREY, N. C. O animal não-humano e seu status moral para a ciência e o Direito no cenário brasileiro. Revista d e Bioética y Derecho, n. 19, p. 2-7, 2010. doi:10.1344/rbd2010.19.7708.

FERREIRA, L. G.; FERREIRA, A. G.; REZENDE, C. N. V.; OLIVEIRA, I. A.; PIRES, M. G. P. A conservação da biodiversidade e sua relação com a Educação Ambiental. Enciclopédia Biosfera, Goiânia, v. 4, n. 5, 2008.

FRAGA, M. E.; MEDEIROS, M. E. S.; NEVES, D. M. Estudo de Aspergilli durante o período de quarentena de psitacídeos do centro de triagem de animais silvestres (CETAS) IBAMA, Seropédica, RJ. Revista Brasileira de Medicina Veterinária, n. 33, v. 2, p. 68-72, 2011.

FRANCO, M. R.; CÂMARA, F. M.; ROCHA, D. C. C.; SOUZA, R. M.; OLIVEIRA, N. J. F. Animais silvestres apreendidos no período de 2002 a 2007 na macrorregião de Montes Claros, Minas Gerais. Enciclopédia Biosfera, Goiânia, v. 8, n. 14, p. 1007-1018, 2012.

FREITAS, A. C. P.; OVIEDO-PASTRANAI, M. E.; VILELA, D. A. R.; PEREIRA, P. L. L.; LOUREIRO, L. O. C.; HADDAD, J. P. A.; MARTINS, N. R. S.; SOARES, D. F. M. Diagnóstico de animais ilegais recebidos no centro de triagem de animais silvestres de Belo Horizonte, Estado de Minas Gerais, no ano de 2011. Ciência Rural, v. 45, n. 1, p.163-170, 2015.

FUCCIO, H.; CARVALHO, E. F.; VARGAS, G. Perfil da caça e dos caçadores no estado do Acre, Brasil. Revista Aportes Andinos, v. 6, p. 1-18, 2003.

GOMES, C. C.; OLIVEIRA, R. L. O tráfico internacional de animais: tratamento normativo e a realidade brasileira. Revista Direito e Liberdade, v. 14, n. 2, p. 33-49, 2012.

HERNANDEZ, E. F. T.; CARVALHO, M. S. O Tráfico de Animais Silvestres no Estado do Paraná. Acta Scientiarum. Human and Social Sciences, v. 28, n. 2, p. 257-266, 2006.

JORGE, R. P. S.; BEISIEGEL, B. M.; LIMA, E. S.; JORGE, M. L. S. P.; LEITE-PITMAN, M. R. P.; PAULA, R. C. Avaliação do estado de conservação do Cachorro-vinagre Speothos venaticus (Lund, 1842) no Brasil. Biodiversidade Brasileira, v. 3, n. 1, p. 179-190, 2013.

KIERULFF, M. C. M.; OLIVEIRA, P. P.; MARTINS, C. S.; PADUA, C. B. V.; PORFÍRIO, S.; OLIVEIRA, M. M.; RYLANDS, A. B.; BEZERRA, A. R. G. F. Manejo para a conservação de primatas brasileiros. A Primatologia no Brasil, v. 10, p. 71-99, 2007. 
KLINK, C. A.; MACHADO, R. B. A conservação do Cerrado brasileiro. Megadiversidade, v. 1, n. 1, p. 147-155, 2005.

LOPES, J. C. A. Operações de fiscalização da fauna: análise, procedimentos e resultados. In: RENCTAS, D. Animais silvestres: 2. ed. Brasília: Dupligráfica, 2003. 17-49p.

LOPES, M. A. E; FERRARI, S. F. Effects of human colonization on the abundance and diversity of mammals in eastern Brazilian Amazonia. Conservation Biology, v. 14, n. 6, p. 1658-1665, 2000.

MACHADO, F. S.; GUIMARÃES, J. C. C.; Luís Antônio Coimbra BORGES, L. A. C.; REZENDE, J. L. P.; CORREAA, B. S. Será que a temática da caça no Brasil tem recebido a atenção necessária? Revista Agrogeoambiental, v. 5, n. 2, p. 49-60, 2013.

MOURA, S. G.; PESSOA, F. B.; OLIVEIRA, F. F.; LUSTOSA, A. H. M.; SOARES, C. B. Animais silvestres recebidos pelo Centro de Triagem do IBAMA no Piauí no ano de 2011. Enciclopédia Biosfera, v.8, n.15; p. 1748-1762, 2012.

NASCIMENTO, L. S.; MACIEL, C. M. R. R.; CORREIA, M. A.; FRIES, D. D.; MACIELJÚNIOR, A. A importância do Parque Municipal da Matinha, Itapetinga-BA, na conservação de espécies de aves ameaçadas pelo tráfico. Enciclopédia Biosfera, v. 6, n. 10, p. 1-8, 2010.

OJIMA, R.; MARTINE, G. Resgates sobre população e ambiente: breve análise da dinâmica democrática e a urbanização nos biomas brasileiros. Idéias, n. 5, p. 55-70.

OKI \& PANDEFF, 2016

PAGANO, I. S. A.; SOUSA, A. E. B. A.; WAGNER, P. G. C; RAMOS, R. T. C. Aves depositadas no Centro de Triagem de Animais Silvestres do IBAMA na Paraíba: uma amostra do tráfico de aves silvestres no estado. Ornithologia, v. 3, n. 2, p. 132-144, 2009.

PEREIRA, W. L. A.; GALO, K. R.; SILVA, K. S. M.; SOARES, M. C. P.; ALVES, M. M. Ocorrência de Hepatites Virais, Helmintíases e Protozooses em Primatas Neotropicais Procedentes de Criação Domiciliar: Afecções de Transmissão Fecal-Oral com Potencial Zoonótico. Revista Pan-Amazônica de Saúde, v. 1, n. 3, p. 57-60, 2010.

PESSOA, T. S. A.; WAGNER, P. G. C.; LANGGUTH, A. Captura e comercialização de animais silvestres no semiárido da Paraiba, Brasil, sob a perspectiva de crianças e adolescentes. Revista Nordestina de Biologia, v. 21, n. 2, p. 79-100, 2013.

PILLAR, V. P.; VÉLEZ, E. Extinção dos Campos Sulinos em Unidades de Conservação: um Fenômeno Natural ou um Problema Ético? Natureza \& Conservação, v. 8, n. 1, p. 
84-86, 2010.

PIRES, G. A.; RODRIGUES, S. F. C.; MACEDO, K. R.; ANDRADE, A. M. F.; FARIKOSKI, I. O.; FREITAS, H. J.; RIBEIRO, V. M. F. Tráfico de animais silvestres e seus produtos no extremo oeste brasileiro. Arquivos de Ciências Veterinárias e Zoologia da UNIPAR, v. 18, n. 4, p. 241-245, 2015.

RENCTAS - Rede Nacional de Combate ao Tráfico de Animais Silvestres. Notícias do Tráfico: Oryzoborus angolensis, 2009. Disponível em: < http://www.renctas.org.br./> Acesso em: 24 out. 2016.

RENCTAS - Rede Nacional de Combate ao Tráfico de Animais Silvestres. 1 Relatório Nacional sobre o Tráfico de Fauna Silvestre, 2014. Disponível em: <http://www.renctas.org.br/> Acesso em: 25 out. 2016.

RIBEIRO, A. S. S.; PALHA, M. D. D.; TOURINHO, M. M.; WHITEMAN, C.; SILVA, A. D. S. Utilização dos recursos naturais por comunidades humanas do Parque Ecoturístico do Guamá, Belém, Pará. Acta Amazônica, Manaus, v. 37, n. 2, p. 235-240, 2007.

RIBEIRO, L. B.; SILVA, M. G. O comércio ilegal põe em risco a diversidade das aves no Brasil. Ciência e Cultura, v. 59, n. 4, p. 4-5, 2007.

ROCHA, M. S. P.; CAVALCANTI, P. C. M.; SOUSA, R. L.; ALVES, R. R. N. Aspectos da comercialização ilegal de aves nas feiras livres de Campina Grande, Paraíba, Brasil. Revista de Biologia e Ciências da Terra, v. 6, n. 2, p. 204-221, 2006.

SAMPAIO, A. B.; SCHMIDT, I. B. Espécies exóticas invasoras em Unidades de Conservação Federais do Brasil. Biodiversidade Brasileira, v. 3, n. 2, p. 32-49, 2013.

SANTOS, E. A. M.; BUENO, M.; ARAÚJO, A. S.; BARROS, I. F. A.; PAES, N. N. G.; RODRIGUES, S. R. W.; CAMPOS, C. E. C.N Aves do Centro de Triagem de Animais Silvestres do Estado do Amapá. Ornithologia, n. 4, v. 2, p. 86-90, 2011.

SEMAS - SECRETARIA DE MEIO AMBIENTE E SUSTENTABILIDADE. Lista de espécies da flora e da fauna ameaçadas no Pará. Belém, 2006. Disponível em: <https://www.semas.pa.gov.br/2009/03/27/9439/> Acesso em: 01 ago. 2016.

SILVA, J. C. R.; SIQUEIRA, D. R.; MARVULO, M. F. V. Ética e bem-estar em animais silvestres - Unidades de conservação. Ciência Veterinária nos trópicos. Recife, v. 11, suplemento 1, p.61-65, 2008.

SOUZA, T. O.; VILELA, D. A. R. Espécies ameaçadas de extinção vítimas do tráfico e criação ilegal de animais silvestres. Atualidades Ornitológicas, n. 176, p. 64-68, 2013. 
VIDOLIN, G. P.; MANGINI, P. R.; MOURA-BRITTO, M.; MUCHAILH, M. C. Programa Estadual de Manejo de Fauna Silvestre Apreendida - Estado do Paraná, Brasil. Caderno de biodiversidade, v. 4, n. 2, p. 37-49, 2004.

ZAGO, D. C. Animais da Fauna Silvestre Mantidos como Animais de Estimação. Monografia (Especialização). Programa de Pós Graduação em Educação Ambiental, Universidade Federal de Santa Maria-RS, 2008. 40p.

ZIMMERMAN, M. E. O mercado negro de espécies silvestres: a luta contra o crime organizado transnacional no comércio ilegal de animais selvagens. Revista Brasileira de Direito Animal, v. 10, p. 11-61, 2012. 